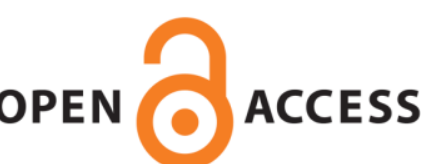

OPEN ACCESS

\author{
UWS Academic Portal
}

\title{
Metabolic and hormonal responses to different resistance training systems in elderly men
}

Paunksnis, Marcos R.; Evangelista, Alexandre Lopes ; Teixeira, Cauê V. La Scala; João, Gustavo Alegretti; Pitta, Rafael M.; Alonso, Angelica C.; Jr, Aylton Figueira; Serra, Andrey Jorge ; Baker, Julien S.; Schoenfeld, Brad Jon; Bocalini, Danilo Sales

Published in:

The Aging Male

DOI:

10.1080/13685538.2017.1379489

Published: 03/04/2018

Document Version

Peer reviewed version

Link to publication on the UWS Academic Portal

Citation for published version (APA):

Paunksnis, M. R., Evangelista, A. L., Teixeira, C. V. L. S., João, G. A., Pitta, R. M., Alonso, A. C., Jr, A. F., Serra, A. J., Baker, J. S., Schoenfeld, B. J., \& Bocalini, D. S. (2018). Metabolic and hormonal responses to different resistance training systems in elderly men. The Aging Male, 21(2), 106-110.

https://doi.org/10.1080/13685538.2017.1379489

\section{General rights}

Copyright and moral rights for the publications made accessible in the UWS Academic Portal are retained by the authors and/or other copyright owners and it is a condition of accessing publications that users recognise and abide by the legal requirements associated with these rights.

If you believe that this document breaches copyright please contact pure@uws.ac.uk providing details, and we will remove access to the work immediately and investigate your claim. 
Metabolic and hormonal responses to different resistance training systems in elderly men.

Translational Physiology Laboratory'. Post Graduate Program in Physical Education and Aging Science, São Judas Tadeu University (USJT), São Paulo, SP, Brazil.

Bioscience departament ${ }^{2}$.Federal University of São Paulo, Santos, SP, Brazil.

Departament of Education Education ${ }^{3}$ and Biophotonic Applied to Health Sciences ${ }^{4}$. Nove de Julho University (UNINOVE), São Paulo, SP, Brazil.

Department of Chronic Disease ${ }^{5}$. Albert Einstein Israelita Hospital, São Paulo, SP, Brazil

Institute for Clinical Exercise \& Health Science ${ }^{6}$. University of the West of Scotland, Almada Street, Hamilton, United Kingdon.

\section{Corresponding author}

Danilo Sales Bocalini

Post Graduation Program in Physical Education and Aging Science

São Judas Tadeu University

Rua Ary Barroso, $n^{\circ}$ 68, apto 105, Torre 1, CEP 09790-240, Ferrazópolis, São Bernardo do Campo, São Paulo, Brazil.

E-mail: bocaliniht@hotmail.com 


\section{ABSTRACT}

To guarantee effects of strength gain during training, which may decrease when the stimulus is insufficient, tedious or non motivational. Training program design should include prescription that ensures that various training methods and overloads are used to maximize strength development. The training adaptations observed include the physiological systems and associated hormonal responses. Objective: To compare acute and sub-acute responses in hormone profile and metabolic parameters in elderly people who participated in two methods of strength training with equalized loads. Methods and materials: After 72 hours of a 1RM test, 12 elderly people (65 \pm 3 years) were randomly assigned to 2 training methods: constant intensity $(\mathrm{Cl}, 3$ series of 10 repetitions with $75 \%$ of $1 \mathrm{RM}$ ) and variable intensity (VI, 1st series: 12 repetitions at $67 \%$ of $1 \mathrm{RM}>2$ nd series: 10 repetitions at $75 \%$ of $1 \mathrm{RM}$ and 3rd series: 8 repetitions at $80 \%$ of $1 \mathrm{RM})$. Both methods included the following exercises: leg press, knee extension and squat with intervals between series standardized at 1 minute, free speed of execution and maximum range of movement were encouraged throughout. Blood samples analyzed included glucose, testosterone, cortisol, growth hormone $(\mathrm{GH})$ and lactate, 2 and 24 hours post intervention. Results: There were no observed differences in glucose, testosterone, $\mathrm{GH}$ and lactate concentrations both at 2 and 24 hours after the execution of the two training methods. However, there were significant increases in the levels of cortisol observed immediately post exercise both protocols. Effect size analysis revealed superiority for the $\mathrm{Cl}$ method in the hormonal profile. The profile observed was favorable to anabolism. Conclusion: Although significant differences were not observed between the two interventions in relation to the hormonal and metabolic parameters analyzed, both training methods promoted a favorable response, with a small superiority for the $\mathrm{Cl}$ method relative to the hormonal profile.

Key-words: strength training, hormones, pyramid, testosterone 


\section{INTRODUCTION}

Strength training (ST) is considered one of the most popular recreational and professional physical activities. Strength training routines are performed by individuals interested in strength development for professional purposes, such as athletes, or by people keen on keeping fit and healthy. The majority of these activities are performed in fitness centers and gymnasiums (THOMPSON, 2016). In addition, ST is also performed for health promotion and rehabilitation, and the benefits of ST are well documented in the scientific literature (GARBER et al., 2011)

It has also been demonstrated that ST promotes significant changes in the metabolic markers associated with strength adaptations such as lactate, glucose, testosterone, cortisol, testosterone-cortisol ratio $(\mathrm{T}: \mathrm{C})$ and growth hormone $(\mathrm{GH})$ (RAASTAD et al. 2000, TREMBLAY et al. 2004, LU et al. 1997, MARIN \& FIGUEIRA JUNIOR 2007). These adaptations can be considered significant in the monitoring and evaluation of the training programs success (CREWTHER \& COOK, 2010)

$\mathrm{T}: \mathrm{C}$ has being used as hormonal marker related to anabolic-catabolic body homeostasis (GAVIGLIO \& COOK, 2014). However, it is not clear how T:C responds to different training methods. Only relatively few studies have investigated the T:C and ST relationship comparing directly the workload (volume and intensity) manipulated between training methods. It is well known that different training strategies, mainly using various training methods, are decisive in promoting musculoskeletal adaptations (LA SCALA TEIXEIRA, 2016). However, when the training stimulus is fixed for a long time period, the scale of adaptation to training diminishes or, even, ceases, which motivates individuals to consider new training methods (HARRIS et al. 2004; SCHOENFELD, 2011).

Despite the literature describing the variability of stimuli needed to promote steady neuromuscular adaptation, the characterization of hormonal responses, mainly $\mathrm{T}: \mathrm{C}^{\prime} \mathrm{s}$, to various training methods is still relatively unexplored in the scientific literature, particularly in relation to elderly populations. Considering the convenience of different methods, the multiple-set series of constant intensity $(\mathrm{Cl})$ and the multiple-set series of variable intensity (VI), also named ascending pyramid (CHARRO et al. 2012), are often used in the strength and fitness industry on a daily basis.

However, from our knowledge, acute and sub-acute hormonal responses using these methods in elderly people with previous experience in ST still are not totally clear. The objective of this study therefore, was to compare the hormonal and acute and sub-acute metabolic responses derived from elderly individuals who participated in two strength training $(\mathrm{Cl}$ and $\mathrm{VI})$ protovols with equalized loads. 


\section{MATERIALS AND METHOD}

\section{Sample}

Following approval from the Committee on Ethics in Research and the completion of the relevant informed consent forms, 12 elderly individuals with previous experience in strength training, but inactive between 6 months and one year, volunteered to participate in the study. Individuals with a known history of cardiometabolic disease, muscle injury (in the last 12 months), continuous or interrupted use of medication or dietary supplementation for up to six months or more, were excluded from the study.

Table 1. Characterization of the sample

\begin{tabular}{lc}
\hline \multicolumn{1}{c}{ Variable } & Average $\mathbf{\text { SSD }}$ \\
\hline Age (years) & $65 \pm 3$ \\
Body mass & $86 \pm 18$ \\
Heigth & $1,75 \pm 0,07$ \\
BMI (kg/m ${ }^{2}$ ) & $28 \pm 4$ \\
\hline Values expressed as the average \pm standard deviation \\
from average. BMl: body mass index.
\end{tabular}

\section{Anthropometric Assessments}

Body composition and anthropometric parameters were assessed following the parameters used in a previous study (BOCALINI et al. 2012). Body mass was determined using a calibrated Toledo digital scale (Model 2096PP/2). Stature was measured with a SANNY stadiometer (model ES2030). Body mass index (BMI) for all subjects was calculated using the values obtained.

\section{Assessment of maximum dynamic strength}

To establish the intensity used for both training protocols it was necessary to determine the 1 repetition maximum (1RM) values for all exercises used in the training program. Prior to the first session, all participants were submitted to 1RM tests for the following exercises, leg press, knee extension and squat. All tests were conducted at the same time of day in an attempt to control the influence of diurnal variation (morning testing). 
One session of testing was considered adequate for the determination of 1RM as all the subjects were familiar with the activities, and all had knowledge of their own individual maximal effort. Prior to the 1RM test, all participants were asked to refrain from exercise for 72 hours before testing. The test was conducted in accordance to the guidelines established by the National Strength and Conditioning Association (BAECHLE 2000). Briefly, the test involved a series of warm-up, with 20 repetitions, followed by adequate increases in load until individual subjects reached 1RM without undue fatigue. A research assistant determined the success or failure of each 1RM test.

\section{Determination of the plasmatic levels of testosterone, cortisol, growth hormone (GH), lactate and glucose}

To determine the plasmatic concentrations of cortisol, testosterone and $\mathrm{GH}$ specific kits were used (DSL-10-2000, Diagnostic Systems Laboratories@, USA). Lactate and glucose levels were obtained using the Accutrend Plus $\AA$. Blood samples were collected before and after 2 and 24 hours post exercise. At each time point $30 \mathrm{ml}$ of blood was collected $20 \mathrm{ml}$ in a tube with fluoridated EDTA and $10 \mathrm{ml}$ in a dry tube. Following collection, the blood was stored under controlled refrigeration at $4^{\circ} \mathrm{C}$, and was then centrifuged and frozen at $-20^{\circ} \mathrm{C}$. I ntra and inter coefficients of variation for blood samples were less than $10 \%$

\section{Procedures}

72 hours post the $1 \mathrm{RM}$ test all participants were randomly assigned to one of the training protocols ( $\mathrm{Cl}$ or $\mathrm{VI}$ ) both with equalized loads. The exercises performed during the study were: leg press, knee extension and squat. During the $\mathrm{Cl}$ protocol all participants performed 3 series of 10 repetitions with $75 \%$ of $1 \mathrm{RM}$ in each exercise. During the IV protocol, the volunteers performed 3 series in each exercise, in the following order: 1) 12 repetitions with $67 \%-1 \mathrm{RM}$; 2) 10 repetitions with $75 \%-1 \mathrm{RM}$; 3) 8 repetitions with $80 \%-1 \mathrm{RM}$. For both protocols, a 1-minute interval for recovery between series was employed, with a free speed of execution and maximum possible range of motion encouraged.

\section{Statistical Analysis}

A Shapiro-Wilks test was applied to verify the normality of the data. When normality was confirmed, and to compare the different exercise phases, a two-way ANOVA test and Tukey's post hoc for repeated measures was used. Significance level 
was $5 \%(p \leq 0,05)$, and the results were presented as the average \pm standard error. Additionally, the size effect (d) was calculated and the statistical tests were performed using a statistical test package, software Graph Pad Prism (version 4.0, San Diego, CA, USA).

\section{RESULTS}

No difference was observed in concentrations of glucose, testosterone, $\mathrm{GH}$ and lactate 2 and $24 \mathrm{~h}$ after both interventions.

Table 2. Metabolic and hormonals parameters before, 2 and 24 hours post execution of variable and constant intensity protocols.

\begin{tabular}{|c|c|c|c|c|c|c|}
\hline \multirow{2}{*}{ Parameters } & \multicolumn{3}{|c|}{$\mathrm{Cl}$} & \multicolumn{3}{|c|}{ VI } \\
\hline & Before & $2 \mathrm{~h}$ & $24 \mathrm{~h}$ & Before & $2 \mathrm{~h}$ & $24 \mathrm{~h}$ \\
\hline Glucose (m/dLI) & $99,4 \pm 4,2$ & $103,1 \pm 4,7$ & $100,4 \pm 4,8$ & $100,1 \pm 2,1$ & $102,1 \pm 3,5$ & $99,2 \pm 2,4$ \\
\hline Testosterone (ng/dL) & $36,0 \pm 12,5$ & $48,4 \pm 9,3$ & $34,4 \pm 14,1$ & $37,4 \pm 13,1$ & $47,7 \pm 9,1$ & $35,4 \pm 13,3$ \\
\hline Cortisol (ug/dL) & $6,7 \pm 3,1$ & $6,4 \pm 4,8^{*}$ & $7,1 \pm 2,3$ & $6,4 \pm 4,3$ & $6,1 \pm 3,1^{*}$ & $5,4 \pm 2,7$ \\
\hline $\mathrm{T}: \mathrm{C}$ & $5,3 \pm 6,2$ & $7,8 \pm 3,4^{*}$ & $4,8 \pm 7,1$ & $5,7 \pm 7,1$ & $7,7 \pm 3,1^{\star}$ & $6,4 \pm 2,7$ \\
\hline $\mathrm{GH}(\mathrm{ng} / \mathrm{mL})$ & $0,89 \pm 2,2$ & $0,70 \pm 3,1$ & $0,80 \pm 1,3$ & $0,99 \pm 2,2$ & $0,85 \pm 5,1$ & $0,87 \pm 1,9$ \\
\hline Lactate $(\mathrm{mMol} / \mathrm{L})$ & $0,9 \pm 0,8$ & $1,26 \pm 2,34$ & $1,1 \pm 1,2$ & $1,1 \pm 0,7$ & $1,46 \pm 1,67$ & $1,0 \pm 0,9$ \\
\hline
\end{tabular}

Values expressed as the average \pm standard deviation of the hormonal and metabolic parameters pre, 2 and 24 hours post performing ST systems' with constant intensity $(\mathrm{Cl})$ and varied intensity $(\mathrm{VI}) .{ }^{*} \mathrm{p}<0,01$ versus before.

However, there was a significant increase in cortisol and T:C after 2 hours using both training methods. After 24 hours no differences were observed between the interventions. Additionally, no significant alterations in the effect size's classifications in all parameters, irrespective of the training protocol used were recorded. (Table 3)

Table 3. Effect Size related to rest.

Cl VI

Parameters

Effect size
Effect size

24h 2h 24h

\begin{tabular}{lcccc}
\hline Glucose $(\mathrm{m} / \mathrm{dLI})$ & 0.88 (Moderate) & 0.23 (Trivial) & 0.95 (Moderate) & 0.42 (Trivial) \\
Testosterona (ng/dL) & 0.99 (Moderate) & 0.12 (Trivial) & 0.78 (Small) & 0.15 (trivial) \\
Cortisol (ug/dL) & 0.41 (Small) & 0.12 (Trivial) & 0.06 (Trivial) & 0.16 (trivial) \\
T:C & 0.40 (Small) & 0.22 (Trivial) & 0.28 (Trivial) & 0.09 (trivial)
\end{tabular}




$\begin{array}{lllll}\mathrm{GH}(\mathrm{ng} / \mathrm{mL}) & -0.08 \text { (Trivial) } & 0.04 \text { (Trivial) } & 0.06 \text { (Trivial) } & 0.05 \text { (Trivial) } \\ \text { Lactato }(\mathrm{mmMol}) & 0.45 \text { (Trivial) } & 0.33 \text { (Trivial) } & 0.51 \text { (Small) } & 0.14 \text { (Trivial) }\end{array}$

Effect size range according to Rhea, (2004) in trained individuals: - trivial $(<0,35)$, small $(0,35-0,80)$; moderate $(0,80-1,0)$, and large $(>1,0)$

\section{DISCUSSION}

Although strength training methods have been routinely used in fitness centers for long periods, studies comparing acute and subacute physiological effects in elderly populations using different strength training methods, in this study $\mathrm{Cl}$ and $\mathrm{VI}$, are rare.

The VI method, also named ascending pyramid, is used for its popularity in changing the training stimuli as regards the conventional strength training format (LA SCALA TEIXEIRA, 2016). The hypothesis for this method is that increasing the load during the training series elevates the magnitude of physiological stress, maximizing the metabolic and hormonal responses to this type of activity.

CHARRO et al. (2010) showed significant changes in blood lactate, cortisol, T:C and $\mathrm{GH}$, without alterations on testosterone and glycaemia. The study used similar protocols to those used in this study the only differences were, that the subjects were young adults. In the present study, both methods $(\mathrm{Cl}, \mathrm{VI})$ resulted in significant elevations in cortisol and $\mathrm{T}: \mathrm{C}$, without alterations in glucose, testosterone and $\mathrm{GH}$ concentrations. Further studies (CHARRO et al., 2012) assessing changes in indirect markers of muscular injury, after traditional and pyramidal exercise protocols, found similar responses in the inflammatory markers (creatine kinase, myoglobin, C-reactive protein) for both methods, confirming the hypothesis that the $\mathrm{VI}$ system seems to provide no additional benefits when the two protocols are compared.

Indeed, some studies suggest that the different metabolic and hormonal responses to ST are associated with a greater range of variation, such as the loads used (example: $30 \%$ versus $80 \%-1 \mathrm{R}$ ) and the number of repetitions performed (example 8-12 versus >25RM) (KRAEMER and RATAMESS, 2005; BUITRAGO et al., 2013). In this study and others (CHARRO et al. 2010; CHARRO et al. 2012) the range of variation of loads and repetitions was small, which may help explain the absence of difference between the interventions.

The fact that there were no differences recorded between $\mathrm{Cl}$ and $\mathrm{VI}$ in the acute and subacute stages agrees with the hypothesis provided by Fonseca et al. (2014).

It is worth mentioning that although the results from this study did not observe significant differences between protocols, the effect size revealed the greater magnitude of response for the $\mathrm{Cl}$ system in the relation $\mathrm{T}: \mathrm{C}$ ratio, 2 hours post training session.. 


\section{CONCLUSION}

Although this study did not find significant differences in the sessions concerning the metabolic and hormonal parameters assessed, both $\mathrm{Cl}$ and $\mathrm{VI}$ provided a favorable response to strength training adaptation in elderly people.

\section{References}

[1] Thompson WR. Worldwide survey of fitness trends for 2017. ACSMs Health Fit J. 2016;20:8-17.

[2] Bocalini DS, Lima LS, Andrade S, et al. Effects of circuit-based exercise program in body composition ofobese older. Clin Interv Aging. 2012;7:551-556.

[3] Bocalini DS, Serra AJ, dos Santos L, et al. Strength training preserves mineral bone density in postmenopausalwomen without use of hormone replacement therapy. J

Aging Health. 2009;21:519-527.

[4] Garber CE, Blissmer B, Deschenes MR, American College of Sports Medicine, et al. American College ofSports Medicine position stand. Quantity and quality of exercise for developing and maintaining cardiorespiratory, musculoskeletal, and neuromotor fitness in apparently healthy adults: guidance for prescribing exercise. Med Sci Sports Exerc. 2011;43:1334-1359.

[5] Lu SS, Lau CP, Tung YF, et al. Lactate and the effects of exercise on testosterone secretion: evidence for the involvement of a cAMP-mediated mechanism. Med Sci Sports Exerc. 1997;29:1048-1054.

[6] Marin DP, Figueira Junior AJ. Responses of serum testosterone and triiodotironine after intense resistance training. Rev Bra. Ci e Mov. 2007;15:31-38.

[7] Raastad T, Bjoro T, Hallen J. Hormonal responses to high- and moderate-intensity strength exercise. Eur J Appl Physiol. 2000;82:121-128.

[8] Sheikholeslami-Vatani D, Slahadin A, Rashad S. Comparison of the effects of resistance exercise orders on number of repetitions, serum IGF-1, testosterone and cortisol levels in normal-weight and obese

men. Asian J Sports Med. 2016;7:e30503.

[9] Tremblay MS, Copeland JL, Helder WV. Effect of training status and exercise mode on endogenous steroid hormones in men. J Appl Physiol. 2004;96:531-539.

[10] La Scala Teixeira CV. Advanced training techniques for hypertrophy. 2nd ed. Charleston (SC): CreateSpace, 2016.

[11] Harris C, Debeliso MA, Spitzer-Gibson TA, et al. The effect of resistance-training intensity on strength-gain response in the older adult. J Strength Cond Res.

2004;18:833-838.

[12] Schoenfeld BJ. Postexercise hypertrophic adaptations: a reexamination of the hormone hypothesis and its applicability to resistance training program design. $\mathrm{J}$ Strength Cond Res. 2013;27:1720-1730.

[13] Charro MA, Aoki MS, Nosaka K, et al. Comparison between multiple sets and halfpyramid resistance exercise bouts for muscle damage profile. Eur J Sport Sci. 2012;12:249-254.

[14] Bocalini DS, Serra AJ, Murad N, et al. Water-vs. landbased exercise: effects on the physical fitness in older women. Geriatr Gerontol Int. 2008;8:265-271.

[15] Bocalini DS, Serra AJ, Rica RL, et al. Repercussions of training and detraining by water-based exercise on the functional fitness and quality of life: a short-term follow up in healthy older women. Clinics. 2010;65:1305-1309.

[16] Cavalcante PAM, Rica RL, Evangelista AL, et al. Effects of exercise intensity on post-exercise hypotension after resistance training session in overweight hypertensive patients. Clin Int Aging. 2015;10:1487-1495. 
[17] Baechle TR, Earle RW. Essentials of strength training and conditioning. Champaign (IL): Human Kinetics; 2000.

[18] Cadore EL, Pinto RS, Lhullier FLR, et al. Physiological effects of concurrent training in elderly men. Int J Sports Med. 2010;31:689-697.

[19] McGuigan MR, Foster C. A new approach to monitoring resistance training. J Strength Cond Res. 2004; 6:42-47.

[20] Charro MA, Aoki MS, Coutts AJ, et al. Hormonal, metabolic and perceptual responses to different resistance training systems. J Sports Med Phys Fitness. 2010;50: 229-234.

[21] Buitrago S, Wirtz N, Yue Z, et al. Mechanical load and physiological responses of for different resistance training methods in bench press exercise. J Strength Cond Res. 2013;27:1091-1100.

[22] Kraemer WJ, Ratamess NA. Hormonal responses and adaptations to resistance exercise and training. Sports Med. 2005;35:339-361.

[23] Ahtiainen JP, Pakarinen A, Alen M, et al. Muscle hypertrophy, hormonal adaptations and strength

development during strength training in strength trained and untrained men. Eur J Appl Physiol. 2003;

89:555-563.

[24] Mangine GT, Hoffman JR, Gonzalez AM, et al. Exercise induced hormone elevations are related to muscle growth. J Strength Cond Res. 2017;1:45-53.

[25] Mccall GE, Byrnes WC, Fleck SJ, et al. Acute and chronic hormonal responses to resistance training

designed to promote muscle hypertrophy. Can J Appl Physiol. 1999;24:96-107. [26] Ronnestad BR, Nygaard H, Raastad T. Physiological elevation of endogenous hormones results in superior strength training adaptation. Eur J Appl Physiol. 2011; 111:2249-2259.

[27] Morton RW, Oikawa SY, Wavell CG, et al. Neither load nor systemic hormones determine resistance training mediated hypertrophy or strength gains in resistance trained young men. J Appl Physiol. 2016;121:129-138.

[28] West DW, Phillips SM. Associations of exercise-induced hormone profiles and gains in strength and hypertrophy in a large cohort after weight training. Eur J Appl Physiol. 2012;112:2693-2702.

[29] West DW, Burd NA, Tang JE, et al. Elevations in ostensibly anabolic hormones with resistance exercise enhance neither training-induced muscle hypertrophy nor strength of the elbow flexors. J Appl Physiol. 2010;108:60-67.

[30] Wilkinson SB, Tarnopolsky MA, Grant EJ, et al. Hypertrophy with unilateral resistance exercise occurs

without increases in endogenous anabolic hormone concentration. Eur J Appl Physiol. 2006;98:546-555. 